\title{
Políticas de la Historia y de la enfermedad: Abraham Valdelomar y La ciudad de los tísicos ${ }^{1}$
}

\author{
José Delpino \\ Northwestern University
}

Tan famosa en Perú como Abraham Valdelomar (1888-1919) es la idea de que sus primeros libros son balbuceos y que, por tanto, no vale la pena gastar tiempo en reflexionar acerca de ellos. También son famosas la etiquetas que condenan estos libros al trastero de la literatura, sin mayor examen, por supuestamente detentar una escritura decadentista, modernista, d'annunziana, juvenil, excesivamente ornamentada, etc. A este conjunto "devaluado" de textos pertenece La ciudad de los tísicos (La correspondencia de Abel Rosell), novela breve originalmente publicada por entregas en 1911 en la revista peruana ilustrada Variedades (1908-1931)².

A la luz de las preocupaciones contemporáneas de la crítica académica, este libro ha despertado renovado interés desde finales del siglo XX. En dos valiosos artículos, Gabriela Nouzeilles y Susana Santos le dedican importantes pasajes a esta novela, con lo que dan vuelta de página a esa larga historia de subestimación que se ha cernido sobre la primera parte de la obra de Valdelomar. Nouzeilles lee la novela como caso paradigmático de la convergencia, en el Modernismo hispanoamericano, de las concepciones de la enfermedad y la autonomía artística. Según ella, La ciudad de los tísicos es construida desde lo que ella llama la retórica de la enfermedad del modernismo hispanoamericano y del decadentismo europeo. Para ella se trata entonces, en resumidas cuentas, de una narración alegórica sobre la autonomía literaria y los deseos y ansiedades en relación con ella. Una narración paradigmática de la legitimación de la autonomía artística que propuso el modernismo en oposición a la modernidad burguesa latinoamericana. Reconoce, no obstante, Nouzeilles, que este libro realiza un gesto -para ella tímido- de actualización en el contexto latinoamericano de la retórica de la enfermedad que lidia con la tradición y la historia de la región (Cfr. Nouzeilles, "La ciudad" 303, 30609). La lectura de Nouzeilles se me presenta como indispensable, no solo porque tiene el mérito de romper con una larga tradición de lugares comunes sobre esta novela, sino porque el análisis de la retórica de la enfermedad que materializa en sus páginas constituye el fundamento, la médula de mi propia lectura, en la medida en que resalta la importancia del vínculo de esta novela con la historia de la región y, específicamente, del Perú.

\footnotetext{
1 En una de sus versiones preliminares, este artículo recibió en 2016 el Beiling Wu Prize in Writing, conferido por Northwestern University al mejor ensayo escrito por los estudiantes del primer año de los doctorados en literatura y cultura de dicha universidad.

2 La ciudad de los tísicos fue publicada al mismo tiempo que La ciudad muerta, otra novela breve de Valdelomar, que salió por entregas en otra revista: La Ilustración Peruana (1909-1913). Estas dos novelas forman una trilogía al lado de una novela inconclusa cuyos originales no se conservan y que Ilevaría por título La ciuda sentimental.
} 
El artículo de Susana Santos me parece también relevante, aunque en un sentido muy distinto. Allí la autora hace una valoración del papel histórico y político de este libro en el contexto de los que podría llamarse la modernización mestiza del campo intelectual peruano, proceso que, en su lectura de la historia del Perú, estaría representado por toda una camada de escritores e intelectuales venidos del interior. Esta idea es sumamente esclarecedora y, aunque Santos solo la desarrolla de pasada, abre la puerta para pensar la posición de esta novela no solo en términos históricos sino también geográficos y raciales. El artículo de Santos sugiere un interesante paralelismo entre la novela y el periplo geográfico e intelectual del autor, que como otros peruanos de la época -sin mayores vínculos con la "aristocracia" limeña que domina el panorama cultural-, viene a hacerse un lugar en la Lima de principios del siglo $\mathrm{XX}$, perturbando los espacios indicados como aceptables para su persona, dentro de los límites de la sociedad peruana de la época y en relación con sus orígenes geográficos y raciales (Cfr. Santos 12). Santos no desarrolla esta idea, pero parece sugerir indirectamente la posibilidad de hacer una lectura alegórica de la Ciudad de los tísicos distinta de la que propone Nouzeilles, pero que al igual que ella, vincula la novela con la historia y la geografía del Perú.

Es a la luz de esta otra posibilidad alegórica de lectura que asoma Santos que propongo una revisión crítica de las ideas de Nouzeilles. Me interesa ver en qué medida la tensión entre ciudad "real" e histórica (Lima) y ciudad patológica y ficticia (la ciudad B.) que la novela propone no tiene que ver tan solo con la contraposición de la autonomía del arte y la enfermedad al utilitarismo y el higienismo de la modernidad burguesa. Propongo que más bien que esta tensión -entre Lima y la ciudad B- tiene que ver con ansiedades mucho más concretas en relación con la historia del Perú y los procesos particulares, por medio de los cuales la modernidad se acelera en este país y en Latinoamérica en general con el cambio de siglo. En este sentido, propongo que la actualización que hace Valdelomar con esta novela de la retórica de la enfermedad y la autonomía artística en el contexto latinoamericano es mucho más que un gesto tímido (Cfr. Nouzeilles, "La ciudad" 303).

Partiendo de las ideas de Nouzeilles y de Santos, deseo explorar aquí la posibilidad de leer esta novela como práctica textual de lectura adulterada de la historia y de su distribución en el espacio de la Nación. Indago cuál sería el ethos ${ }^{3}$ que propone la mirada histórica del libro, en la medida en que dicha mirada va encarnada en un sujeto ficcional que, por medio de la lectura y los paseos, se desdobla y se contagia. Me interesa finalmente pensar qué papel desempeña en dicho proyecto el cuerpo imaginado como espacio privilegiado de adulteraciones. Se trata de ver cómo, dentro de los límites de su discursividad, esta ficción constituye y promociona un cierto ethos

\footnotetext{
3 Se utilizan las nociones de ethos, subjetividad y estética de la subjetividad en el sentido que les confiere Michel Foucault en la última parte de su obra a partir del segundo tomo de la Historia de la sexualidad y es sus cursos del Collège de France a partir de 1979, así como en los desarrollos que a partir de ellos puso en marcha Gilles Deleuze desde mediados de la década de 1980 (Foucault, Estética; Foucault, La hermenéutica; Foucault, El coraje de la verdad; Foucault, El gobierno de sí; Foucault, El gobierno de los vivos; Deleuze, Foucault; Deleuze, La subjetivación).
} 
-práctica subjetiva- en relación con la historia, el espacio y la enfermedad. Y, además, cómo constituye un intento temprano de pensar la posibilidad de la democratización y nacionalización del esteticismo.

El primer capítulo de La ciudad de los tísicos cuenta en primera persona las peripecias decadentes de un personaje narrador anónimo, que se halla de visita en Lima. Es un visitante del interior del Perú, con cierto aire de aristócrata y hombre de mundo. La acción abarca el periodo impreciso que corresponde a los pocos días que este personaje pasa en la ciudad, y en los que su atención se divide en dos mayores obsesiones: en primer lugar está la persecución de una mujer misteriosa -en el apartado titulado "El perfume"4-y, en segundo lugar -en "Rosas coloniales"-, están los paseos por diversas edificaciones, lugares históricos y museos de la ciudad que lo llevan a reconstruir episodios particulares de la historia del Perú en una especie de ensayo o crónica histórica ficticia.

La parte más extensa de este primer capítulo se corresponde a la narración de esa especie de paseo histórico, al que se entrega el narrador después de abortar su intento de provocar eróticamente a la mujer misteriosa que había estado persiguiendo. Este paseo es narrado en tiempo presente, como una experiencia en vivo que claramente sustituye -a modo de escape- el anterior intento de la persecución y provocación amorosa entre dos desconocidos. El sustituto del deseo es, entonces, la crónica de un paseo por Lima, en el que el personaje narrador ensaya una particular mirada histórica sobre el pasado del Perú. Se trata de una narración híbrida que -sobre todo en su espacio original de circulación, el de la novela por entregas en una revista semanal ilustrada- juega a la ambigüedad de los géneros y reta la débil frontera entre ficción y no-ficción que el lector tendría que establecer en este caso, aunque solo sea tentativamente. Dicha frontera, pues, se torna imprecisa y ese paseo se desarrolla como una crónica periodística y al mismo tiempo como ficción, como una escritura que yuxtapone lugares, edificios, ideas y objetos emblemáticos de Lima y del Perú y que los inserta en una cadena discursiva en donde el deseo y la provocación amorosa -producida por contagio epistolar- aparece sustituida abruptamente por el deseo de una Historia nacional proyectada en el espacio y accesible al paseante.

Más que un caso paradigmático de retórica modernista de la enfermedad, esta novela se me presenta en su estructura como interrupción e intervención de esa narrativa para producir algo más bien distinto, una especie de "metamodernismo" y "paramodernismo" que no solo exacerba los efectos del desdoblamiento de la estructura narrativa en diversos niveles narrativos, sino que parece constituir la novela como un artefacto que genera efectos hacia fuera, hacia el mismo espacio donde circula -la revista donde fue publicada en un primer momento- $y$, por extensión, hacia el espacio público en general. Es totalmente plausible que, al encontrarse con las primeras entregas de esta novela, algunos lectores de la revista se hayan preguntado en su

\footnotetext{
4 El episodio de la persecución de la mujer es sumamente breve e intenso, ocupa pocas páginas que quitan el aliento: la acción se desarrolla explícitamente en un corto espacio de horas y es contada alternativamente como recuerdo -en tiempo pasado- y como experiencia vivida en el justo momento en que se la narra -en tiempo presente-.
} 
momento, con ansiedad, desconcierto, o bien con aire cómplice, sobre la indecisión genérica que el texto estampaba, sobre todo cuando se refiere a la crónica histórica que despliega inmediatamente después de la persecución de la mujer. ¿Es el texto una crónica? ¿Un ensayo histórico? ¿Quién es el cronista? ¿Cuál es la autoridad de su mirada? ¿Cuál es la voz que desarrolla esa especie de ensayo histórico y crónica urbana que es el segundo apartado? ¿Es de ficción o no-ficción esa voz historizante? ¿Es Valdelomar mismo como ensayista, como periodista, como cronista, como autor ya conocido? ¿Son en serio las ideas que allí se proponen acerca del Perú o son producto del delirio del personaje decadente que narra la novela en primer plano? ¿Es que acaso la novela -al menos en esa parte- es algo que realmente le ocurrió al autor, a Valdelomar mismo, el que viste y calza como un dandi? ¿Qué sentido tiene desbordar la novela decadente modernista hacia el espacio periodístico en que la nación es imaginada como comunidad (Anderson)?

Conviene recordar aquí que el autor se había hecho célebre, un año antes de la publicación de la novela, con una serie de crónicas, supuestamente de no-ficción. Se trata de las crónicas que envía durante casi dos meses a El Diario - un periódico de circulación nacional- bajo el título de "Con la argelina al viento"5, y que escribe desde la Escuela Militar de Chorrillos, recinto al que se había incorporado ante el peligro de una conflagración con Ecuador (Cfr. Tamayo Vargas 3). En dichos textos el autor firma como: "Abraham Valdelomar. Soldado de artillería". No sería difícil pensar en un lector desprevenido que tomara alguna de esas entregas de la novela por una crónica, de igual manera que las crónicas desde la escuela militar. Pero más allá de esas posibilidades, es evidente que estamos en presencia de un juego con las fronteras entre ficción y no-ficción.

El segundo capítulo de la novela, en su sección más evidentemente decadentista, está compuesto mayormente por las cartas que un amigo del narrador -Abel Rosell- le había enviado desde la ciudad B. -la ciudad de los tísicos-, lugar donde se había retirado para vivir su tuberculosis por recomendación de los médicos. El primer apartado de este capítulo pone en escena estas cartas y las inserta en el flujo de la narración que se viene desarrollando:

Voy a leer solamente las cartas que a este viaje -el último- se refieren. En ellas está condensado todo su espíritu que sutilizaron las fiebres y la anemia. [...]. Desde allí [desde la ciudad B.] me escribió todas sus cartas que ahora voy a leer, porque quiero tener vivo, cálido, el recuerdo de su vida; hoy que muerto él, he de ir a B., para visitar su ciudad y su tumba. Son las once de la noche [...] voy a entrar, una vez más, leyendo las cartas, en la ciudad de los tísicos. Me parece que voy a hablar con Abel... (Valdelomar 207-08).

5 Estas crónicas se publicaron entre el 12 de abril y el 9 de junio de 1910. 
En un giro marcadamente metaficcional, el narrador presenta estas cartas transcritas directamente en el cuerpo de la novela, sincronizando su propia lectura obsesiva con la lectura que hace el lector externo de La ciudad de los tísicos. La novela, así, pretende contagiar al lector de esa reincidencia, de esa obsesión por la vida moribunda de Abel Rosell y por la extraña ciudad donde habitaba y vivía su enfermedad, al mismo tiempo que convierte al narrador en lector mismo de la novela. Así, justo antes de iniciar su posible viaje a la ciudad B., el narrador se dispone, como lector, a experimentar de nuevo la vida del amigo de manera interpuesta, textual, por medio de su lectura. No se trata, sin embargo, de todas las cartas que su amigo le envió durante sus innumerables viajes, sino solamente de las cartas que le resultan irresistibles e interesantes en grado sumo: las cartas escritas por Abel en estado avanzado de enfermedad, cuando experimenta estados alterados en que las ideas, el cuerpo, el espíritu, la percepción y la conciencia se trastocan.

La ciudad de los tísicos demarca en la geografía de ese Perú de ficción, un territorio adulterado. A través de las cartas de Abel, el narrador principal o interpuesto, deja de narrar y se convierte en un lector transportado a dicho espacio, en un lector afectado por una enfermedad ajena que desea. En un sentido extremo podemos incluso decir que se convierte él mismo en Abel Rosell por medio del dispositivo de las cartas: "Podría repetir de memoria algunas de ellas. Me parece como si hubiera vivido yo en esa ciudad pavorosa y trágica [...] Con mi mente he ido a sus fiestas y he estado a su lado, he ido a sus rondas y me parecía estar oculto en el follaje" (Valdelomar 20708). La estructura de la novela pasa a ser entonces un juego metaficcional de máscaras. El personaje que inicialmente narra la historia ahora pasa a convertirse en una sombra de Abel Rosell y se afantasma, para llevarnos a nosotros de la mano, paso a paso, línea a línea por unas cartas que cuentan una historia en el límite ya de lo fantástico, de lo espectral. No obstante, como veremos más adelante, entramos a un espacio, la ciudad de los tísicos, donde los sujetos, debilitados por la enfermedad, no se afantasman, sino que en la misma medida en que su cuerpo se altera, empiezan a constituirse como fuertes y originales subjetividades que retan las convenciones en relación con la enfermedad, el amor, el sexo y la muerte -lo que en gran medida reproduce la retórica modernista y decadentista acerca del vínculo entre enfermedad, genialidad y arte-. La novela nos presenta entonces una paradoja: lo que podría suponerse la capa más decadente, espectral y fantástica del libro -debido al estilo en que es contada y los niveles de "afectación" que la enmarcan-, termina plantándose ante el lector como el mundo más sólido y potente de toda la ficción, como el espacio donde los personajes, como subjetividades, demandan con más contundencia una existencia desde la diferencia. Es el narrador, el que en la lejanía se afantasma durante la mayor parte del libro. En el segundo capítulo, la ciudad B. se planta ante el lector con máxima contundencia de una realidad no a través de su narrador epistolar-que siempre es un personaje, dubitativo, afantasmado-, sino en esta comunidad de tísicos.

Es allí, dentro de las fronteras de ese mundo leído en segundo grado, donde se concentra la mayor parte de la acción, la carne dramática de la narración, el cuerpo denso de la trama. Es tanta la intensidad y la extensión allí, comparadas con la primera parte que sirve de marco para la historia, que 
hasta ahora, unánimemente, los críticos han tenido a dejar de lado el paseo histórico que la precede, y, por ende, a restarle importancia, para entonces descartar a La ciudad de los tísicos como novela inmadura de juventud, propia de un decadentismo epigonal. Sin embargo, el paseo histórico es precisamente esa otra instancia fuerte de la narración, que la des-afantasma. Si tenemos en cuenta esa parte específica del primer capítulo, se puede afirmar que en ambas historias -la historia marco y la historia epistolar-, se legisla con la misma intensidad sobre la realidad, sobre de la división de lo sensible para proponer sus trastocamiento (Rancière).

El narrador principal, antes de abismarse en el recuerdo epistolar de la ciudad de los muertos -y disolverse en las subjetividades tísicas-, ensaya ante el lector una crónica personalísima de la historia del Perú, donde también vemos actuando una subjetividad fuerte que de nuevo legisla la distribución de lo sensible. Es la tensión entre esas dos densidades discursivas donde se juega -a mi modo de ver- el proyecto político, el ethos crítico de esta novela. Es allí donde podemos leer, no el balbuceo de un proyecto literario ni tampoco una propuesta tímida de reconfiguración del modernismo, sino la libertad experimental que constituye ese proyecto literario desde sus primeras páginas en un gesto alucinante de relecturas superpuestas. Carácter experimental que, además, lo separa tanto del modernismo hispanoamericano como del decadentismo europeo, y que lo acerca más a cierta literatura experimental que, a inicios del siglo XX, adelanta la eclosión vanguardista en el continente. Por su estructura narrativa compleja, que coloca en contigüidad la Historia del Perú y la historia de una ciudad cuasifantástica; por su estilo evasivo y su extraño tratamiento de los temas decadentes, más que un producto literario hecho a la medida de la influencia de formas literarias de moda en la Lima de la época -el decadentismo y el modernismo-; me parece, más bien, que esta novela ensambla elementos decadentistas, modernistas, impresionistas y otros de muy diversa índole para construir algo distinto. La ciudad de los tísicos funciona como un artefacto literario extraño, experimental, que resulta difícil de clasificar, y que ha sido despachado rápidamente por casi todas las lecturas críticas precisamente por esa cualidad extraña.

Ambos, Abel -el narrador epistolar-y su amigo -el narrador interpuesto o principal-, son personajes adulterados. Ambos viven en un estado permanente de alteración -de su ideas, acciones y cuerpos- que los hace personajes impúdicos. En el caso de Abel, el origen de esa alteración es la enfermedad, así como el emplazamiento en el que decide vivirla: la ciudad B., especie de utopía de las alteraciones. En el caso de su amigo, el narrador, esta alteración de la norma está asociada a dos fuentes: por un lado, una particular relación con el pasado del Perú que se empeña en su "actualización" en el presente; por el otro, la lectura de las cartas y la enfermedad de Abel Rosell y el milieu de la ciudad de los tísicos, que dichas cartas le contagian metafóricamente.

Asimismo, puede decirse que ambos personajes -el narrador y su amigoson presencias interpuestas, emplazamientos de la mirada. Son personajes "afantasmados", sabemos poco de ellos directamente. Es decir, su espesor como personajes - para decirlo de alguna forma- es absolutamente externo: son observadores empedernidos. Gracias a estas dos miradas puestas en secuencia, conectadas una con la otra, nos enteramos de los otros personajes 
que habitan en sus propias narraciones más que acerca de ellos mismos. En ese sentido, su performance subjetivo no es el de un mundo interior que se descifra, sino más bien el de un ethos que se construye a partir de un régimen de mirada preocupado por los otros, abismado en su absoluta diferencia, en su proliferación de subjetividades patológicas e históricas, individuales y colectivas. En este sentido, el contagio que la enfermedad tiene con las voces narradoras y sobre el estilo mismo de la novela aparece comedido, contenido, y no se traduce tanto en el performance literario del delirio, sino que más bien el acto de narrar aparece en sintonía con el delirio, para resituar tal experiencia y reconvertirla en una especie de lucidez solo posible si la enfermedad aparece mediada y el contagio diferido y solo experimentado como metáfora.

Los personajes, objetos y situaciones que nos muestra ambos regímenes de mirada al yuxtaponerse -ya sean los personajes de la vida de Rosell (los tísicos) o los personajes de la historia del Perú- son todos presencias absolutamente retadoras, potentes. Aparecen barrocamente enmarcados, escenificados detrás de varias capas de estructura narrativa que componen la novela. Son personajes debilitados por la circunstancia de la muerte o la ruina que el devenir de la historia deja a su paso, estas presencias -personajes, objetos y situaciones-, sin embargo, no lucen realmente debilitados, sino que por el contrario se apoderan de la máquina narrativa para convertirse en su centro, en su pulpa de significación. Es a ellos a los que los dos narradores dirigen todo su deseo, toda su energía narrativa. Son ellos, además, los que constituyen el espesor de los emplazamientos narrativos: la ciudad histórica (Lima) y la ciudad patológica (la ciudad B.). La Lima del primer capítulo adquiere sustancia no en la descripción de sus calles -que se afantasma y vacían en su realidad presente como por contagio del narrador- sino en la descripción de su historia proyectada en los territorios que la conforman. La ciudad de los tísicos (o ciudad B.), por su parte, adquiere particularidad y potencia en estos enfermos que la habitan, y que tiene el tiempo y la mente trastocados.

Como ya lo he señalado, toda la novela se fundamenta en la tensión entre estos dos espacios distanciados, en sus equivalencias y disonancias, que permiten imaginar comunidades ausentes pero sustantivas. Son emplazamientos tan distintos que parecen ser mundos diferentes e incomunicados y hasta el final creemos que el único punto de contacto que tienen son las cartas y el acto de su lectura. Sabemos que el amigo de Abel, el narrador, ha llegado a Lima y que allí se prepara para tomar un tren rumbo a la ciudad B. Esa es una decisión que ya está tomada y lo sabemos pronto en el desarrollo de la historia. El viaje es inminente, pero los dos días que nos separan de él se dilatan a lo largo de toda la novela -incluida la lectura de las cartas en compañía del narrador interpuesto, que es un lector reincidente, obsesivo$y$, al final, después del encuentro del narrador con la mujer misteriosa esa decisión se llena de irrealidad, no sabemos nunca si el personaje realizará el viaje. Su realización parece llenarse de irrealidad y de dudas. Sin embargo, al final de la novela, el narrador descubre que aquella mujer es el punto de contacto entre los dos mundos. Es una mujer que viaja cada quince días a visitar a su marido, es la mujer misteriosa que aparece en las cartas de Abel. Esta mujer -Magdalena- se convierte entonces en la única persona capaz de 
conectar aquellos dos emplazamientos, pero, no obstante, pretender disuadir al narrador de concretar el viaje: el vínculo entre los dos espacios sustantivos de la novela es, entonces, el principal agente de su distanciamiento.

Como se ha visto, la novela se inicia con la interrupción de los paseos ociosos del narrador. Este se encontraba en estado de vacancia en Lima esperando retomar su viaje dos días después rumbo a la ciudad $B$, pero esta espera, con sus paseos, lecturas, ocios y meditaciones, es interrumpida por un encuentro con una mujer misteriosa. Dicho encuentro desata una persecución amorosa súbita al amparo del anonimato citadino -al final de la novela sabremos que se trataba de una mujer casada-. Este inicio es una narración intensa que lleva por título "El perfume", y que es, de por sí, el objeto elusivo que desencadena los hechos. Así, este flirteo amoroso, de persecución y provocación, entre el narrador y una mujer vestida de negro, interrumpe la normalidad burguesa en que deambula el narrador, sirve de desencadenante del paseo histórico al inicio de la novela y de puente con la ciudad de lo tísicos al final de la misma: "iAdmirable! La mujer, pálida, nerviosa, me sigue, me sigue aprisa, como una fiera a un corderillo, las narices abiertas, el cuerpo inclinado hacia adelante. Sigo desviando el camino y ella detrás (Valdelomar 198-99)6".

La normalidad del decoro no se restaura sino que se invierten los papeles. Sin embargo, no es esto -una ficción de amor adulterado o un adúltero- lo que me interesa resaltar ahora aquí. Me interesa más bien constatar cómo esta primera historia -la aventura del perfume-, adelanta una característica central de todo el relato. La novela toda se convierte en el diferimiento de la vida del narrador interpuesto, el que se encuentra como poseído por su mirada -y por su deseo-, y solo vive a través de la mirada que deposita en la vida de otros, como escondido, mirando por la pequeña apertura de su emplazamiento siempre anónimo, escondido, solitario7. Así, observa a la mujer y la persigue; así, se empeña en revivir el pasado de Perú y de Lima leyendo su espacio; así, lee las cartas de Abel y vive la vida de Abel. Todo es un diferimiento. La temporalidad de este personaje se halla como suspendida, a la espera del viaje y de la decisión de ver definitivamente a la mujer misteriosa. Así ese lapso de dos días se extiende y alberga dos historias solo aparentemente ajenas: la historia del Perú y, luego la historia de Abel y de un sinnúmero de tísicos admirables. En este estado de indecisión, el narrador interpuesto se convierte en un largo diferimiento; $y$ es él mismo el lienzo activo donde se estampa el "espectáculo" vital de los otros, un ethos marcadamente relacional. En la huida apresurada de su propia aventura amorosa inminente -aventura que luego se verá que era un potencial adulterio-, el narrador se transporta apresurado a los jardines del virrey Amat, una ruina

\footnotetext{
6 La cita continúa así: "Entonces tengo miedo, debe ser una loca o una excéntrica, y principia a obsesionarme la dama vestida de negro. Me arrepiento de haberla provocado, ha sido una locura, una cosa impensada. Pero ella me sigue, tres vueltas más y me alcanza. ¿Qué hacer? Cuando ya... Cruzo directamente casi corriendo, ella apura el paso, y me va a tocar, y llego al coche: -iArranca! Un fuetazo. Los caballos han partido violentamente y yo he sentido que me quitaban un gran peso de encima. -iY la dama!..." (Valdelomar 198-99).

7 No es sin embargo un ethos suspendido, pasivo, lo que la novela propone como ethos histórico y nacional.
} 
viva de la historia, donde las flores, los árboles, las fuentes, dan testimonio de un escándalo amoroso del Perú colonial:

[...] aquello más que un jardín de flores es un paraíso de recuerdos donde el amor hizo nidos, levantó estatuas bajo las frondas, perfumó rincones, santificó glorietas e inmortalizó pecados.

La Perricholi con sus gasas, sus cintas de seda bordadas, sus careys esculpidos, sus hebillados zapatos de raso y su gran abanico rosado hizo una página de encantador pecado para la historia galante de la Colonia. Ella puso sonrisas de amor, miradas de arte, coqueterías de cortesana y de artista en una época en donde la melancolía, el dolor, el temor de Dios, hacían el amor en silencio y sin pompa [...] Fue, pues, la Perricholi, quien copiándose en los espejos naturales del Paseo de Aguas, o paseando en los jardines del virrey sus esbelteces de artista, de gran mujer y de gran apasionada, alegró no solo las tardes silenciosas y enervantes de la Colonia, sino que escribió una página de la Historia, no con las plumas de ánade que marcaban los pergaminos, sino con el dardo del dios griego que encendía los corazones (Valdelomar 200).

El diferimiento del deseo no desencadena aquí la culpa, sino una reflexión histórica que podría pasar por amanerada, "decadentista", frívola8. Pero la puesta en escena del tema es solo frívola en apariencia: a partir de una escena fallida de pecado burgués, salta a la Colonia y yuxtapone esos dos tiempos con la descripción de una escena análoga de pecado y escandalo colonial. La deseada escena de flirteo incierto -donde además la mujer toma el rol más activo- es sustituida por otra escena más lejana que aparece dignificada -en toda su carnalidad- como un acontecimiento importante en la historia del país, y en la que una mujer asume también un rol activo. La Perricholi (17481819) - María Micaela Villegas y Hurtado de Mendoza, una célebre actriz del Perú colonial- entabla amores con la máxima autoridad del virreinato. Pero el virrey es aquí solo un decorado que sobrevive por carambola el paso del tiempo. La agencia histórica se le otorga en este caso a la mujer, la Perricholi, que rompe el código colonial "copiándose" en los jardines del virrey y en el devenir de la historia9. El impudor de la Perricholi es una alegría que quiebra la calma de una sociedad pasada que se presenta como "estática", como una resistencia al cambio. La fragilidad de ese cuerpo -de ese solo individuo que se copia en los estanques de esa heterotopía que son los jardines- lo que copia no es la imagen de ese "pecado", como espectáculo, sino la agilidad para movilizar una situación solidificada, para resonar su persona en un solo acto. Así el ethos suspendido del narrador como observador individual tiene como principal práctica la de imaginar posibilidades de comunidad nacional en la historia y en el cuerpo de los otros, en otras subjetividades potentes, disruptivas y movilizadoras.

8 Y en todo caso lo es, pero de una forma compleja y positiva.

9 Esta metáfora tomada de la novela de Valdelomar me parece especialmente aguda y llena de posibilidades. Por ejemplo, en el contexto de este trabajo, "Copiar" la propia imagen puede interpretarse aquí, me parece, como "copiar" la propia subjetividad en los espejos de la historia, proyectarla al futuro como efecto o potencia más allá de lo individual. 
Todo este recorrido por la historia del Perú -titulado "Rosas coloniales"- es la crónica del hallazgo -al paso- de objetos, personajes, ideas, del pasado colonial, que pueda el texto hacer resonar en su presente de diferimientos: estas ruinas vivas de un pasado humano van a ser convertidas, una por una, en imágenes dialécticas que engarzan con el presente diversos momentos de la historia del Perú. La crónica, el paseo y el museo no son aquí artefactos de disciplinamiento, sino, más bien, dispositivos de emplazamiento, de inversión, de cuestionamiento que, entre otras cosas, difieren marcadamente del mecanismo tan recurrido en el siglo XIX y principios del XX, de convertir lo anormal, las zonas adulteradas de la nación, en espectáculo que se mira con ansia inquisitoria (Cfr. Bouzaglo 27-28, 48, 68; Cfr. Molloy 13). La sexualidad, en esta novela, es precisamente el tema que más se evade en su concreción espectacular descarnada. Sus líneas están llenas de puntos suspensivos que indeterminan las escenas de la sexualidad fuera de norma, de modo que dicha sexualidad no se convierte nunca en espectáculo inquisitorial y pornográfico, en una obscenidad normativizadora: por ejemplo, el ménage à trois que culmina la fiesta de matrimonio de Margarita y Armando -dos de lo tísicos que viven en B. -10 .

Al salir de los jardines del virrey -y de la Perricholi-, el narrador se traslada a un salón de pintura donde lo aguardan los lienzos olvidados de Ignacio Merino (1817-1876). En sensuales écfrasis verbales el narrador nos presenta los cuadros y describe, junto a ellos, a su pintor: "un pincel republicano que, alejándose de sus días, evocó las glorias, leyendas y trofeos coloniales" (Valdelomar 200), para inmortalizarlos y coger en su propio presente los agonizantes, últimos restos de la Colonia. El narrador -y por medio de él el autor del libro- se ve de repente en el espejo de Merino. Es él también el artista que busca coger con sus manos los restos vivos de un pasado que muere, pero a la vez, los restos de un pasado que persiste. En 1911, Lima no es todavía una ciudad desbordada como Buenos Aires, es más bien una de esas pequeñas ciudades que, como Caracas o Bogotá, mantiene vivo su pasado colonial como el peso de una gran piedra. Como señala con tino Susana Santos, a pesar de que sus murallas fueron demolidas en 1868, Lima sigue siendo una ciudad de murallas invisibles, no ligadas tanto a un proyecto de burgués modernidad -neocolonial- como a un pasado colonial que persiste en otras formas y que limita y resiste la incorporación de nuevos sujetos a la dinámica cultural, social y económica de la capital (Santos 11-12).

\footnotetext{
10 Este ménage à trois junta a Margarita y Armando -los novios-con Abel -el narrador de las cartas-. Este cuenta la escena con humor -su sorpresa ante la situación es hilarante- y el acto aparece velado y develado intermitentemente por la noche y los relámpagos, por el vino, por los puntos suspensivos. Los detalles son evadidos, pero el acto en sí como hecho es presentada con potencia simbólica, descaro, alegría, sorpresa, humor, y con potente doble sentido. Ocurre con una facilidad pasmosa que no da tiempo a nombrar nada. La escena en sí, al igual que sus detalles, queda incompleta, se la arrebata al deseo fetichista de la mirada y al mismo tiempo se la convierte en la imagen de una posibilidad de ruptura que tiene su correlato en el narrador interpuesto -en sus recientes paseos históricos, en su tentativa con la mujer misteriosa, en sus recuerdos de Perricholi-. Me parece fundamental, decisivo, que no se trata de una escena de adulterio, sino de una escena de adulteración del matrimonio y de la fiesta que lo consuma.
} 
Otro de los elementos que la mirada del narrador interpuesto privilegia durante su paseo histórico son los huacos y la muerte. Los huacos son piezas de cerámica prehispánica de Perú con un gran valor estético y que, en algunos casos, pueden representar incluso escenas eróticas, sexuales, de muy diversa índole. Con excepción de ciertas zonas de lo que hoy es México y otros contados lugares y culturas, la gama de actos sexuales que eran aceptados en el mundo prehispánico era muy amplia. Es sugestivo que el mismo narrador que al describir en las primeras páginas a la mujer misteriosa la compara a los grabados de pintores japoneses como Utamaro y Houkosay -artistas que muy abiertamente elaboraron escenas sexo-diversas explícitas-, sea el narrador que nos habla de la Perricholi y que luego se decanta por hacer una revisión exhaustiva de la importancia cultural e histórica de los huacos: una herencia material de poder disruptivo en el contexto del entresiglo latinoamericano:

Si cabe idealismo en el arte, venid a buscarlo en los huacos. Venid a admirar símbolos, a interpretar miradas, a leer historias trágicas. iInterpretad la risa de los huacos! [...]

iLa risa de estas figurillas de barro, la mirada de estos ojos sin luz, la actitud de estos hombres que luchan! No es una risa sana, definida, risa de pueblo feliz bajo el sol fecundante. Es una mueca enfermiza, un gesto de ironía. Es la parte de caricaturas de aquellas edades. Un arte original, porque hay en él la escritura simbólica, el culto a la verdad y la caricatura filosófica. Estos hombres del Gran Imperio del Sol no tuvieron pinturas, ni libros, ni monedas, no tuvieron teatro, de manera que sus pensamientos, sus deseos, sus creencias, sus amarguras, su alma toda la pusieron en sus huacos.

Estos objetos de arcilla son, pues, obras de filosofía, piezas estatuarias, lienzos heráldicos, libros de historia. En casi todos la risa es el motivo de la fisonomía [...]

En este salón del museo donde la República exhibe en pecaminosa promiscuidad la edad colonial y la incaica, puede resucitar, aunque no íntegra, la vida de los hijos del Sol $[\ldots]$

[...] Y, dominándolo todo, como objeto de un culto más grande, sus flautas, sus quenas, sus tamborcillos. Flautas que cantan amores, quenas que dicen penas y amarguras, tambores que ensordecen y aterran. Todo el espíritu de esos artistas, de esas mujeres, de esos amantes que nos hablan desde el misterio de sus siglos remotos y dudosos. ¿Y estos objetos muertos, estos trajes de pasadas fiestas raras, estos arreos descoloridos ya por el tiempo; estas muertas glorias del sol y de su imperio, mudas y abismadas, olvidadas o mistificadas por los profanos, quién sabe si hablan más de su perdida gloria que los últimos restos 
de la raza que hoy se pierde en los campos, se entumece en las punas y llora sin saber por qué en lo alto de las colinas incaicas?... (Valdelomar 202-03).

Se puede apreciar aquí el primero de los temas que acapara la reflexión en la sección referente a los huacos: el narrador lee estos objetos de arte como la consumación del encuentro entre arte y sociedad, en la medida en que tienen el poder de encarnar una filosofía y de constituir el arte de todo un pueblo -un arte, que además, está totalmente integrado a su vida-. El pasado prehispánico se honra, sin monumentalizarlo completamente; se intenta pensarlo al mismo tiempo que se lo intercala con analogías vivas en las mentes de la época: la moda, la religión, la vida cotidiana. No hay un desarrollo de la sexualidad en los huacos, pero se roza el tema cuando se menciona que en él aparecían también "amantes". El paseo es general, solo se desarrollan a profundidad dos temas: por un lado, el tema de la potencia del arte para hacer vivir a un pueblo y proyectar su modo de vida más allá de la desaparición de sus glorias, como potencia, como ruina poderosa; y, por el otro, el tema de la representación de la muerte en el pasado prehispánico.

Al final del paseo, el narrador hace un contrapunto entre los huacos y las imágenes religiosas del cristianismo: contienda cuyo resultado se hace explícito antes de que el paseo termine y que es la manifestación de una clara preferencia por la supuesta celebración incaica de la muerte:

La idea de la muerte colocada sobre la vida misma. Entre los incas la muerte no es cesación sino actividad, cambio de lugar; y esta muerte incaica no tiene la guadaña que corta, que mata, que hace verter sangre, sino el tambor que aterra, que señala una hora, que recuerda una cita. Y cita sonriendo, con su graciosa, amable y amada sonrisa [...] (Valdelomar 204).

El paseante, ese esteta decadente que recorre la historia, legisla sobre la división de lo sensible que distribuye el pasado de la Nación ${ }^{11}$. Pone todas sus energías sensuales en esta seria tarea y genera una especie de atmósfera extraña, donde su misión se hace tanto con despreocupación como urgencia, como si el tiempo futuro se avecinara y esa sociedad, envejecida en la que vive, necesitara renovarse en su pasado roto, para regenerarse como colectivo de subjetividades potentes. Tanto este pasado de los huacos como las reflexiones estéticas del sabio Alphonsin mientras conversa con Abel en la ciudad B., sugieren, además, que esta regeneración nacional basada en el cuerpo y en la historia, debe tener al arte como otras de sus piedras angulares. No obstante que se trate de un arte por venir, un arte por crear, por inventar. Los huacos, como fragmentos de un pasado en cierta medida inaccesible ya, perdido, sepultado por la Colonia, vienen a ser análogos a las

11 El final del paseo es la huida de la Catedral de Lima: el paseante había sumergido su mirada profana, laica, desenfadada, diletante en una misa, y decide irse al inicio de una oración demasiado sacra. El personaje sale y el paseo termina. Se hace de noche. Nuestro narrador interpuesto comienza entonces la relectura de las cartas de Abel antes de su viaje a la ciudad $\mathrm{B}$. 
cartas decadentistas de Abel Rossel, en la medida en que estas cartas son la única vía de acceso a un pasado que, o bien ya ha desaparecido, o bien nunca puede ser accedido porque su única entrada es la propia muerte. Sin embargo, tanto en los huacos como en las cartas el pasado vive y revive. Son objetos estéticos que tienen la potencia de condensar una comunidad entera, de ser su patrimonio simbólico y su elemento de cohesión: ya sea la sociedad -en sentido amplio- que habita el pasado del Perú o ya bien esa sociedad más pequeña de enfermos que es la ciudad de los tísicos.

Así como el paseo histórico es un inventario de objetos, situaciones y personas del pasado, las cartas de Abel Rosell son un inventario de tísicos y las situaciones que estos comparten. Estos personajes retan al lector con una impaciente fuerza vital que se despreocupa de las convenciones. Son casos, más no prototipos, casos subjetivos, no casos clínicos. La enfermedad -específicamente la tuberculosis- es en esta ciudad una especie de ejercicio espiritual que se realiza con convicción. No es una enfermedad que solo se padece y de la que se muere, es una enfermedad de la que se vive. Estos aristócratas tísicos, además, son aristócratas por convicción, aristócratas cuyos títulos de abolengo son en primer término la enfermedad, luego, en segundo término, la condición económica que les permite estos retiros ociosos y llenos de lujo. En algunos casos, incluso, encontramos algunos personajes que podrían incluso carecer de esos medios económicos y que, sin embargo, habitan la ciudad como mucho más que sirvientes: son, sobre todo, y por encima de todo, tísicos. Y todos los tísicos, así como los huacos y algunos personajes históricos como La Perricholi, son entonces imágenes dialécticas de un ethos histórico que evita morir de la enfermedad del pasado y, más bien, intenta vivir del pasado como potencia, como enfermedad vital, disruptiva y movilizadora. Así, la novela pone en un mismo plano al arte y las subjetividades disruptivas como formas éticas y estéticas de construir comunidad.

En la ciudad B. converge y se potencia la diversidad de las subjetividades. Cada uno de estos personajes es un caso sui generis, una manifestación de la particularidad extrema, y tiene una manera distinta de constituirse como sujeto. Lo único que los une es la rareza disruptiva de su particularidad, así como el precepto relativamente libre de tener tisis y entregarse a vivirla. La ciudad B. es entonces una heterotopía ficticia construida a partir de un referente histórico más o menos claro, Chosica y Jauja, pero también a partir del conocimiento de una realidad común a las sociedades latinoamericanas de la época: el retiro del ambiente tóxico de la ciudad es casi un ritual moderno, institución que se práctica de las más diversas maneras. No solo los aristócratas enfermos de tisis, como el fundador histórico de Chosica, optan por esta práctica. Pero lo que en la historia de Latinoamérica era mayormente práctica higiénica de curación, o ejercicio de la paranoia de la mudanza que protege de la diversidad cultural, política y étnica de las ciudades en crecimiento, Valdelomar lo convierte -según he descrito- en algo muy distinto.

La ciudad de los tísicos es una ficción somática invertida, muy distinta a las ficciones somáticas del naturalismo argentino, por ejemplo. Si bien la novela de Valdelomar es una ficción estructurada en un proyecto epistemológico de indagación e investigación de lo corporal (Cfr. Nouzeilles, "La ciudad" 298-303), no se trata de la pesquisa clínica del cuerpo enfermo con el fin de 
establecer o recortar, por exclusión, los contornos futuros de una sociedad "perfecta" o "deseable" (Cfr. Nouzeilles, "La ciudad" 298-303). Los habitantes de la ciudad de los tísicos han "renunciado a sus patrias lejanas" (Valdelomar 225), y han asumido la enfermedad, la muerte, la contaminación y la diversidad como patrias. Así como señala Nouzeilles, la ciudad de los tísicos está construida como el reverso narrativo de la ciudad de los higienistas, y sería una heterotopía o contrautopía (Cfr. Nouzeilles, Ficciones somáticas 303)12. A partir del ejercicio espiritual de la enfermedad, hacen posible esta suerte de comunidad extraña, que desmedicaliza la vida, paradójicamente, en la medida en que está integrada precisamente por enfermos. El reverso de la ciudad de los higienistas resulta ser algo así como una ciudad de estetas de la propia subjetividad. Pero la diversidad de resultados es desconcertante. Aunque hay dandis, y estos ocupan posiciones importantes en su arreglo político, la ciudad de los tísicos está lejos de ser una ciudad solo para dandis aristócratas. En todo caso, la enfermedad como práctica espiritual parece ser una metáfora de la composición del sujeto como obra de arte en el contexto de una heterotopía de desmedicalización de la cultura. El emplazamiento por excelencia de la medicalización con privilegios, la ciudad burguesa de retiro y curación, es invertido y convertido en un lugar donde la enfermedad y la muerte son formas de potenciar la vida: un espacio alegórico liminar, donde se ensaya la disolución de los privilegios y los controles, tanto del pasado colonial como del futuro modernizado.

Esta inversión de la utopía paranoica de los higienistas se completa en la medida en que este emplazamiento de enfermos que es $B$. no funciona tanto como un modelo a seguir, sino como un modelo a leer, mediado por una distancia y articulado con otros elementos como el paseo histórico. En este sentido, la novela se presenta como alegoría compleja que extiende a otros territorios las ficciones somáticas, no solo invirtiéndolas: una operación que la novela toma de la tradición modernista y decadentista y que, entre otras cosas, le dan prioridad a la perspectiva del enfermo genial por encima de la del médico, de modo que el enfermo reclama los sentidos de la enfermedad para sí (Cfr. Nouzeilles, Ficciones somáticas 297).

Mi lectura de La ciudad de los tísicos propone que esta heterotopía somática da un paso más allá de esta inversión heredada. La novela entonces se propone como una alegoría de negociación entre las dos "alternativas": una en clave de novela decadentista, y la otra de crónica histórica urbana. La estructura de la novela, su trama de varios niveles, las hace extrañamente reconciliables en el cuerpo del narrador interpuesto, en el emplazamiento de su mirada que lo interpreta todo desde la máxima exterioridad del paseante, del snob de lo propio. La novela decadentista como declaración de "autonomía" del arte y del sujeto, aparecen aquí conjugada con la novela de la historia de la nación, con la necesidad de pensar el pasado de la Nación en un sentido colectivo, más allá de los límites del modernismo. Lo que la novela propone es ver desde el presente esas dos posibilidades literarias

\footnotetext{
12 "Construida como reverso de la ciudad utópica de los higienistas, la ciudad de los tísicos reproduce, por su mera separación del resto de la sociedad y por la vigencia de un conjunto exclusivo de reglas de conducta, la autonomía de la práctica artística" (Nouzeilles, Ficciones somáticas 303).
} 
como discursos no definitivos y en interacción. En este sentido, ni el pasado y presente indígena, ni el pasado colonial ni el presente modernizador, ni el cosmopolitismo, ni el aristocratismo estético se presentan como alternativas excluyentes, sino que se conciben como prácticas que deben mezclarse para producir otra cosa. El modelo no es entonces ni la ciudad de los higienistas ni la ciudad de los "aristócratas" tísicos, ni tampoco la reinstauración del pasado indígena o de la "grandeza" colonial estancada, sino más bien algo que está todavía por venir y que surge de una capacidad dialéctica de lectura que no evade ninguno de estos materiales ficcionalizados del pasado y de la imaginación, y que los proyecta en dos espacios concretos del territorio de la nación: Lima -la capital- y Chosica/Jauja -la ciudad de retiro y sanación-. Se trata de una proyección de la ficción hacia esos emplazamientos exteriores, y no tan solo de la mera representación de dichos emplazamientos "reales" hacia el interior de la novela, en el interior de la novela.

Primero, Lima, contra la cual se yuxtaponen la Lima y el Perú ficticios de la heterotopía histórica por medio de la ambigüedad de los géneros con los que se hace la crónica del paseo por el pasado, un paseo que reta en el contexto de la novela por entregas la frontera entre realidad y ficción. Segundo, Jauja y Chosica, ciudades de retiro -ligadas históricamente a la tuberculosis de una forma muy específica-, referentes evidentes para un lector peruano de la época, contra los que se yuxtapone la ciudad de los tísicos -la ciudad B-13. Tanto Jauja como Chosica eran parte del imaginario médico, periodístico y "turístico" de las cercanías de la capital desde la Colonia. De hecho, en el caso específico de la tuberculosis, desde muy temprano, a mediados del siglo XIX, fue muy marcada la idea de que el clima seco y de altura de estos dos poblados era beneficioso para el tratamiento de dicha enfermedad y, además, se inició un largo proceso de discusión y planificación -bastante publicitados en la prensa al menos desde 1901- para la construcción de dispensarios o sanatorios para tuberculosos en alguno de los poblados. Estos proyectos eran bien conocidos por los habitantes de Lima, tanto como era conocida la tuberculosis -que era considerado un grave problema de salud en Perú durante el siglo XIX-; sin embargo, no es sino en 1918 -7 años después de la publicación de la novela-, que comienza a construirse el Sanatorio de Olavegoya en Jauja, el que se inaugura en 1922 (Cfr. Neyra Ramírez 44, 63-65, $67-69,71,73)$. Por otro lado, así como el tren de la novela conectaba Lima con la ciudad B, fuera de la ficción, el Ferrocarril Central del Perú conectaba Chosica con Lima desde 1875, y a Jauja más recientemente, desde 1908 (Cfr.

13 Me parece revelador que uno de los intérpretes de la vida y la obra de Valdelomar, Luis Alberto Sánchez, sostenga todavía en 1969, ya con bastante perspectiva y distancia, que la ciudad de los tísicos era una mera "crónica poemática sobre la ciudad de Chosica", para luego pasar a descartarla, paradójicamente, como falsa, balbuceante novela decadente, plagada de decoraciones y -ya decididamente con pánico- como toda "una sinfonía de perfumes y una letanía de manos" (Sánchez 74-75). Sus observaciones -solo aparentemente contradictoriasrevelan la adyacencia e, incluso, la convergencia, del miedo al indecoro literario y el miedo a la confusión de los géneros; pero, en todo caso, son una muestra interesante de cómo la novela es apreciada indecisa y ansiosamente en sus ambigüedades de género y verdad, y en su relación -estrecha, desbordada- con los espacios no ficcionales del territorio de la Nación y su historia. Parte de la historia del rechazo y devaluación de los primeros textos de Valdelomar -incluyendo a esta novela- no es otra cosa que una respuesta ansiosa ante los que considero el núcleo de su propuesta estética. 
Galessio 65, 69). Esto había contribuido, sin duda, a que ambos poblados formaran parte del temprano imaginario del turismo peruano del cambio de siglo -promocionado por el turismo y la publicidad-, lo que iniciaba la lenta transformación de una idea más aristocrática/burguesa de ciudad de retiro en la noción más moderna y propiamente burguesa de ciudad turística, de esparcimiento y curación (Armas Asín).

La ciudad B. puede asociarse con Jauja y Chosica, en primer lugar, porque la utopía medicalizada de un sanatorio como proyecto para esas "ciudades" era de conocimiento público desde muy temprano. Además, la cercanía a la Lima de la novela y la conexión por tren, hace inevitable el referente territorial concreto, geográfico de esos dos poblados, Jauja y Chosica, que estaban siendo transformados rápidamente por la llegada del ferrocarril -en el caso de Chosica desde 1875 y en el caso de Jauja desde 1908-, y que eran referentes turísticos y curativos para el limeño, promocionados en la prensa y en la publicidad, así como en la narrativa diaria de los habitantes de la ciudad. Son imaginarios colectivos, discursividades, con las que la novela dialoga. Y la inevitable posibilidad de la asociación/proyección casi automática por parte del lector de la ciudad B. en esos espacios, referentes e imaginarios no-ficticios, es algo que la novela explota para derramar los códigos del modernismo y el decadentismo hacia una exterioridad discursiva, más allá de su reafirmación estetizante, y para pensar y problematizar más directamente el proyecto de nación y la necesidad de cambiar el Perú.

El esteticismo de Valdelomar y su deseo de ser una especie de héroe popular $^{14}$ no entran en contradicción, sino que se amalgaman en una especie de subjetividad autoral paradójica que cruza elementos de Rubén Darío y Oscar Wilde, con rasgos prefascistas del Gabrielle D'Annunzio anterior a la primera guerra mundial, así como con una inclinación temprana a ser también figura política15. En ese sentido, me parece que es necesario entender

14 Este deseo tiene numerables instancias: su enlistamiento en Escuela Militar de Chorrillos para una posible guerra con Ecuador y la publicación de sus crónicas de esa experiencia en la prensa; la publicación durante toda su carrera literaria de los más diversos artículos y crónicas referentes a moda, arte, guerra, la "sociedad" limeña, política y pare de contar; su participación en el movimiento político populista en apoyo a la candidatura y presidencia de Guillermo Billinghurst; su gira de conferencias por los lugares más recónditos de Perú; y, entre otras cosas, su gira de campaña política que también recorrió en Perú y en donde muere. Su participación en el billinghurismo es especialmente relevante en el contexto de publicación de La ciudad de los tísicos (1911), ya que es precisamente entre 1910 y 1912 que se involucra en dicho movimiento: y así despliega "con sorprendente pasión, actividades que a primera vista parecen incompatibles: por un lado, practica un dandismo clásico y escribe novelas decadentes; por el otro, despliega una fervorosa actividad política como agitador y militante del populismo billinghurista que promovió la democratización de la sociedad a partir de 1912" (Bernabé 124).

15 Según Mónica Bernabé: Valdelomar "vivió en carne propia la contradicción rubendariana: si bien no fue un poeta para las multitudes, supo que indefectiblemente tenía que ir hacia ellas. En una sociedad jerárquica y aristocratizante como era la limeña a principios del siglo $X X$ y donde la consagración de un escritor dependía de sus vinculaciones con el poder político e intelectual dominante, Abraham Valdelomar, de origen humilde y provinciano, decidió realizar la hazaña de procurarse un público solo en base de su talento. Pero antes que un público lector, Valdelomar encontró un público espectador en la medida en que para ser leído primero necesitó ser visto. De ahí que la pose constituyera su 'difícil arte predilecto'" 
La ciudad de los tísicos como parte de un proyecto tentativo, muchas veces errático, pero profundamente potente; un proyecto de democratización y de politización del esteticismo, que se inicia con su obra temprana y que continúa hasta su muerte ${ }^{16}$. Esta tensión que se aprecia en Valdelomar como figura pública, no es otra cosa que el correlato de esa otra tensión que vemos en muchos de sus textos y especialmente en La ciudad de los tísicos: la tensión entre el esteticismo, la historia de la nación y sus cuerpos y subjetividades disruptivas, y las posibilidades del presente y el futuro cercano. Esta es una tensión que, en el caso de la novela, alegoriza la necesidad, la urgencia, el llamado a comenzar a crear tanto un arte nuevo como un colectivo de subjetividades nuevas, tentativamente, poniendo todo en riesgo, y a partir de una relectura disruptiva de la historia de Perú y de su presente, así como de la transformación y derrame de los códigos estéticos disponibles hacia las exterioridades discursivas de la nación. La creación, la práctica de este ethos estético, histórico y político, que en gran medida servirá para echar las bases del advenimiento de las vanguardias en el Perú, es un deseo encarnado no solo en Valdelomar y sus textos, sino en gran parte de la juventud intelectual migrante y mestiza que se va apoderando de Lima, y a la que pertenece Valdelomar como uno de sus primeros líderes aglutinadores. Así, podemos entender la profecía ambigua que hace el sabio tísico Alphonsin acerca del futuro de la ciudad de los tísicos, al mismo tiempo como la profecía de la indetenible modernización y como la necesidad de su contrapartida: una contrapartida que sea, no la repetición del esteticismo modernista y el decadentismo, sino el advenimiento de ese arte nuevo y de una primera "vanguardia" de jóvenes que tienen la esperanza arriesgada de querer cambiar al Perú con él como herramienta pero en tensión con esa modernidad burguesa y torpe:

Hoy, Alphonsin me ha leído estos versos que le envío. Son una visión de la ciudad. Al principio, el tísico describe amorosamente su patria [...] Dice cómo va a morir, pero tiene el temor lírico de la nueva ciudad. Él me ha dicho: - Cuando vengan los fuertes, los sanos, los musculosos a buscar el metal de los cerros, ya los tísicos no vendrán. $Y$ esos hombres sanos y rosados, torpes ambiciosos y buenos, profanarán el encanto y el recuerdo de nuestar ciudad. En los rincones donde se besan los tísicos, ellos fecundarán nuestras vidas, y en la gruta donde ora Rosalinda, la triste, ellos instalarán sus maquinarias, en lugar de jazmineros habrá chimeneas; el humo de

(Bernabé 122). La esfera pública como terreno para el ejercicio del arte es un elemento fundamental para entender a Valdelomar, pero también para entender sus textos, con su notoria tendencia al derrame.

16 Aunque Mariátegui es uno de los primeros en reconocer esta tensión entre esteticismo y preocupación política o social en la obra del Valdelomar y en la figura pública y autoral misma de Valdelomar como valor-signo, a mi parecer exagera la importancia que tiene el decadentismo en la obra inicial de Valdelomar, para así descartarla o quitarle importancia como obra, y tiende a identificar - lo que ya se ha convertido un lugar común de la críticael aspecto más positivo de esta tensión con la obra "madura" del autor, la que atiende más explícitamente a temas nacionales (Cfr. Mariátegui 235-42). 
las máquinas manchará la limpidez azul del cielo y el sonido estridente de las sirenas destrozará la paz de la aldea. iY nuestras tumbas, Abel, nuestras tumbas profanadas! Sacarán nuestros huesos para quemarlos, regarán líquidos desinfectantes, volverán a hacer las casas, y sobre la vida neustra que pasó, sobre nuestros huesos carcomidos, sobre nuestro recuerdo, edificarán su vida. Una nueva vida, gérmenes nuevos, generaciones fecundas [...] (Valdelomar 225-26).

\section{Obras citadas}

Anderson, Benedict. Comunidades imaginadas: Reflexiones sobre el origen y la difusión del nacionalismo. Fondo de Cultura Económica, 2016.

Armas Asín, Fernando. Una historia del turismo en el Perú: El Estado, los visitantes y los empresarios (1800-2009). Universidad de San Martín de Porres, Fondo Editorial, 2018.

Bernabé, Mónica. Vidas de artista: Bohemia y dandismo en Mariátegui, Valdelomar y Eguren (Lima 1911-1922). Beatriz Viterbo; Instituto de Estudios Peruanos, 2006.

Bouzaglo, Nathalie. Ficción adulterada: Pasiones ilícitas del entresiglo venezolano. 2016.

Deleuze, Gilles. Foucault. Paidós, 1987. La subjetivación: Curso sobre Foucault: Tomo III. Vol. 3, Cactus, 2015.

Foucault, Michel. Del gobierno de los vivos curso en el Collège de France (1979-1980). Fondo de Cultura Económica, 2014.

El coraje de la verdad: El gobierno de sí y de los otros II. Curso en el Collège de france (1983-1984). Fondo de Cultura Económica, 2010. El gobierno de sí y de los otros: Curso en el Collège de France (19821983). Fondo de Cultura Económica, 2011.

Estética, ética y hermenéutica. Obras esenciales. Editado por Ángel Gabilondo, vol. III, Paidós, 1999.

La hermenéutica del sujeto: Curso en el Collège de France (19811982). Fondo de Cultura Económica, 2002.

Galessio, Elio. Ferrocarriles del Perú: Un viaje a través de su historia. Aruntani, 2007.

Mariátegui, José Carlos. 7 ensayos de interpretación de la realidad peruana. Editado por Aníbal Quijano, Biblioteca Ayacucho, 2007.

Molloy, Sylvia. "La política de la pose". Las culturas de fin de siglo en América Latina, editado por Josefina Ludmer, Beatriz Viterbo Editora, 1994, pp. 128-38.

Neyra Ramírez, José. Imágenes históricas de la medicina peruana. Universidad Nacional Mayor de San Marcos, 1999.

Nouzeilles, Gabriela. Ficciones somáticas: naturalismo, nacionalismo y políticas médicas del cuerpo (Argentina 1880-1910). Beatriz Viterbo, 2000. "La ciudad de los tísicos: tuberculosis y autonomía". Anales de la literatura española contemporánea, vol. 23, núm. 1/2, 1998, pp. 295-313.

Rancière, Jacques. Dissensus: On Politics and Aesthetics. 2015.

Sánchez, Luis Alberto. Valdelomar o La belle époque. Fondo de Cultura Económica, 1969. 
Santos, Susana. "De una ciudad de tísicos a Lima sin murallas: la modernidad mestiza de Abraham Valdelomar". Taller de Letras, núm. 38, 2006, pp. 9-17.

Tamayo Vargas, Augusto. "Abraham Valdelomar: Vida y obra". revihispmod Revista Hispánica Moderna, vol. 35, núm. 1-2, 1969, pp. 1-44.

Valdelomar, Abraham. Obras: textos y dibujos. Editado por Willy F Pinto Gamboa y Luis Alberto Sánchez, Editorial Pizarro, 1979. 
